\title{
No Surface Cooling over Antarctica from the Negative Greenhouse Effect Associated with Instantaneous Quadrupling of $\mathrm{CO}_{2}$ Concentrations ${ }^{\mathscr{O}}$
}

\author{
KAREN L. SMITH \\ University of Toronto Scarborough, Toronto, Canada, and Lamont-Doherty Earth Observatory, Palisades, New York \\ GABRIEL CHIODO \\ Department of Applied Physics and Applied Mathematics, Columbia University, New York, New York \\ MiCHAEL PREVIDI \\ Lamont-Doherty Earth Observatory, Palisades, New York

\section{LORENZO M. POLVANI} \\ Department of Applied Physics and Applied Mathematics, Department of Earth and Environmental Sciences, \\ and Lamont-Doherty Earth Observatory, Columbia University, New York, New York
}

(Manuscript received 19 June 2017, in final form 3 October 2017)

\begin{abstract}
Over the highest elevations of Antarctica, during many months of the year, air near the surface is colder than in much of the overlying atmosphere. This unique feature of the Antarctic atmosphere has been shown to result in a negative greenhouse effect and a negative instantaneous radiative forcing at the top of the atmosphere $\left(\mathrm{RF}_{\text {TOA:INST }}\right)$, when carbon dioxide $\left(\mathrm{CO}_{2}\right)$ concentrations are increased, and it has been suggested that this effect might play some role in te recent cooling trends observed over East Antarctica. Here, using fully coupled global climate model integrations, in addition to radiative transfer model calculations, the authors confirm the existence of such a negative $\mathrm{RF}_{\text {TOA:INST }}$ over parts of Antarctica in response to an instantaneous quadrupling of $\mathrm{CO}_{2}$. However, it is also shown that the instantaneous radiative forcing at the tropopause $\left(\mathrm{RF}_{\mathrm{TP}: I N S T}\right)$ is positive. Further, the negative $\mathrm{RF}_{\mathrm{TOA}: I N S T}$ lasts only a few days following the imposed perturbation, and rapidly disappears as the stratosphere cools in response to increased $\mathrm{CO}_{2}$. As a consequence, like the $\mathrm{RF}_{\mathrm{TP}: \mathrm{INST}}$, the stratosphere-adjusted radiative forcing at the TOA is positive over all of Antarctica and, in the model presented herein, surface temperatures increase everywhere over that continent in response to quadrupled $\mathrm{CO}_{2}$. The results, therefore, clearly demonstrate that the curious negative instantaneous radiative forcing plays no role in the recently observed East Antarctic cooling.
\end{abstract}

\section{Introduction}

Over the past decade, a large effort has been focused on reconstructing Antarctic surface air temperature (SAT) from in situ, satellite, and reanalysis datasets, in order to gain a better understanding of how this highly sensitive region has been changing (Chapman and

Supplemental information related to this paper is available at the Journals Online website: https://doi.org/10.1175/JCLID-17-0418.s1.

Corresponding author: Karen L. Smith, karen.smith@utoronto.
Walsh 2007; Monaghan et al. 2008; Steig et al. 2009; O'Donnell et al. 2011; Bromwich et al. 2013; Nicolas and Bromwich 2014). These reconstructions have revealed considerable spatial asymmetry and strong seasonality in SAT trends over the satellite era, including statistically significant warming in West Antarctica in austral spring [September-November (SON)] and, surprisingly, a clear although statistically insignificant cooling in East Antarctica in austral autumn [March-May (MAM)] (Schneider et al. 2012; Nicolas and Bromwich 2014; Smith and Polvani 2017).

A number of mechanisms have been suggested to explain these SAT trends, typically relating to changes in the atmospheric circulation associated either with 
stratospheric ozone depletion (Thompson and Solomon 2002; Marshall 2007; McLandress et al. 2011; Nicolas and Bromwich 2014) or with tropical teleconnections (Ding et al. 2011; Schneider et al. 2012; Simpkins et al. 2014; Li et al. 2014; Clem and Fogt 2015; Clem and Renwick 2015; Fogt and Wovrosh 2015).

An intriguing new mechanism was proposed by Schmithüsen et al. (2015, hereafter S15), who reported that the existence of a negative greenhouse effect (GHE) and a negative instantaneous radiative forcing at the top of the atmosphere (TOA) associated with increasing $\mathrm{CO}_{2}$ might contribute to the cooling of East Antarctica. As in S15, we illustrate this instantaneous radiative forcing in a simple two-level framework (e.g., Marshall and Plumb 2007), in which the longwave (LW) flux at the TOA takes the simple form

$$
F_{\mathrm{TOA}: \mathrm{LW}}=-\left(1-\varepsilon_{\mathrm{ATM}}\right) \sigma T_{\mathrm{SFC}}^{4}-\varepsilon_{\mathrm{ATM}} \sigma T_{\mathrm{ATM}}^{4},
$$

where $T_{\mathrm{SFC}}$ and $T_{\mathrm{ATM}}$ are the temperatures of the surface and atmosphere, respectively, $\varepsilon_{\text {ATM }}$ is the LW atmospheric absorptivity/emissivity, and $\sigma$ is the StefanBoltzmann constant; downward fluxes are positive, as per the usual convention. The instantaneous change in $F_{\mathrm{TOA}: \mathrm{LW}}$ due to a change in $\varepsilon_{\mathrm{ATM}}$ (for constant $T_{\mathrm{SFC}}$ and $T_{\mathrm{ATM}}$ ), such as due to an increase in $\mathrm{CO}_{2}$ concentrations, can be written as

$$
\frac{\partial F_{\mathrm{TOA}: \mathrm{LW}}}{\partial \varepsilon_{\mathrm{ATM}}}=\sigma\left(T_{\mathrm{SFC}}^{4}-T_{\mathrm{ATM}}^{4}\right) .
$$

We refer to this as the instantaneous radiative forcing at the TOA (hereafter, $\mathrm{RF}_{\text {TOA:INST }}$ ). Note that, in this simple two-level framework, the right-hand side (RHS) of Eq. (2) is proportional to the greenhouse effect $\left[\mathrm{GHE}=\varepsilon_{\mathrm{ATM}} \sigma\left(T_{\mathrm{SFC}}^{4}-T_{\mathrm{ATM}}^{4}\right)\right]$. The key point here is that nearly everywhere on Earth $T_{\mathrm{ATM}}$ is lower than $T_{\mathrm{SFC}}$, making the RHS of Eq. (2) positive. Over Antarctica, however, for many months of the year $T_{\text {АTM }}$ can be substantially higher than $T_{\mathrm{SFC}}$, making the RHS of Eq. (2) negative: hence the negative greenhouse effect or negative $\mathrm{RF}_{\text {TOA:INST }}$.

This peculiar negative greenhouse effect, only found over the coldest regions of Antarctica, was originally observed by Hanel et al. (1972, see their Fig. 12d), using an infrared spectrometer aboard one of the early Nimbus-4 meteorological satellites. It has been recently examined in S15, who computed the nearly instantaneous $\mathrm{RF}_{\mathrm{TOA}: \mathrm{INST}}$ to a quadrupling of $\mathrm{CO}_{2}$ concentrations using both a line-by-line radiative transfer model and an atmospheric general circulation model (GCM).

In this paper we confirm and extend the findings of S15. Specifically, using both an offline radiative transfer model and ensembles of fully coupled atmosphere-ocean-land-sea ice GCM integrations, we demonstrate that the while the $\mathrm{RF}_{\text {TOA:INST }}$ is indeed negative over Antarctica in certain seasons, the instantaneous radiative forcing at the tropopause $\left(\mathrm{RF}_{\text {TP:INST }}\right)$ is positive. In addition, we show that the negative $\mathrm{RF}_{\mathrm{TOA}}$ :INST is very short-lived, and that the rapid cooling of the polar stratosphere negates it within a couple of weeks after quadrupling of $\mathrm{CO}_{2}$ concentrations $\left(4 \times \mathrm{CO}_{2}\right)$. We also explore the possibility that the negative $\mathrm{RF}_{\mathrm{TOA}}$ :INST might be amplified by climate feedbacks, but we find that at no time and at no location over Antarctica does the surface cool following $4 \times \mathrm{CO}_{2}$ in our model.

\section{Methods}

\section{a. Models}

The GCM we employ is the Specified Chemistry version of the Whole Atmosphere Community Climate Model (SC-WACCM), a stratosphere-resolving version of the National Center for Atmospheric Research (NCAR) Community Earth System Model (CESM1). The atmospheric component of SC-WACCM has 66 vertical levels with a model top at $140 \mathrm{~km}$, a horizontal resolution of $1.9^{\circ} \times 2.5^{\circ}$, specialized parameterizations for gravity waves, and specified middle atmosphere chemistry [for details, see Smith et al. (2014)]. This atmospheric model is coupled to land, ocean, and sea ice components identical to those described in Marsh et al. (2013).

In addition to SC-WACCM, we use the Parallel Offline Radiative Transfer (PORT) model to calculate the instantaneous radiative forcing at the TOA and tropopause and the stratosphere-adjusted radiative forcing at the TOA following $4 \times \mathrm{CO}_{2}$. We note that PORT consists of the radiative transfer component of SC-WACCM, and, when stratospheric temperatures are allowed to adjust radiatively, employs a fixed dynamical heating assumption above the tropopause but with tropospheric and surface properties held fixed (Conley et al. 2013).

\section{b. Integrations}

With PORT, we compute the seasonally varying instantaneous radiative forcing as the instantaneous LW flux difference between two PORT integrations with fixed temperatures throughout the troposphere and stratosphere: one with $4 \times \mathrm{CO}_{2}(1148 \mathrm{ppm})$ and one with preindustrial $\mathrm{CO}_{2}$ concentrations (287 ppm) using the climatology from a single, 1-yrlong ensemble member of the preindustrial SC-WACCM integrations described below. We compute the instantaneous radiative forcing both at the 
TOA $\left(\mathrm{RF}_{\mathrm{TOA}: \mathrm{INST}} \equiv \Delta F_{\mathrm{TOA}: \mathrm{LW}}\right.$, where $\Delta$ is the difference between the $4 \times \mathrm{CO}_{2}$ integration and the preindustrial integration) and the tropopause $\left(\mathrm{RF}_{\mathrm{TP}: \mathrm{INST}} \equiv \Delta F_{\mathrm{TP}: \mathrm{LW}}\right)$. The stratosphere-adjusted version, $\mathrm{RF}_{\mathrm{TOA}: \mathrm{ADJ}}$, is computed using the same experimental setup, except that the we now run PORT allowing stratospheric temperatures to adjust radiatively to the imposed $\mathrm{CO}_{2}$ perturbation and $\Delta F_{\mathrm{TOA}: \mathrm{LW}}$ is calculated using averages over 1-yr-long PORT integrations, starting at 1 January.

While PORT is an excellent tool for computing radiative forcing, it provides no information about the subsequent response of Antarctic SAT to $4 \times \mathrm{CO}_{2}$ in the coupled climate system. To examine that response in the presence of all physically consistent model adjustments and feedbacks, we conduct a suite of 10-member SCWACCM integration ensembles. To construct the 10-member ensembles, we perturb the initial conditions as in Kay et al. (2015). Specifically, from an existing 500-yr preindustrial control integration (Smith et al. 2014), for each month of the year we branch two 1-yr-long, 10-member ensembles of integrations, one with preindustrial forcings and one with $4 \times \mathrm{CO}_{2}$, for a total of 240 integrations. For each pair of integrations, we then calculate the "instantaneous" radiative forcings (for SC-WACCM, we use the average over the first 5 days), $\mathrm{RF}_{\mathrm{TOA}: \mathrm{INST}}$ and $\mathrm{RF}_{\mathrm{TP}: \mathrm{INST}}$, and the stratosphere-adjusted radiative forcing, $\mathrm{RF}_{\mathrm{TOA}: \mathrm{ADJ}}$, as well as the SAT and surface flux responses.

One final note about terminology: in the text below, the average over the 12 responses (one for initialization in each month) will be referred to as the "12-month mean" to distinguish it from the "annual mean," which we reserve to indicate the mean over one calendar year of model integration, as customary in the climate literature. We also use the term "3-month mean" in an analogous way to describe the average over the responses for specific seasons.

\section{Results}

We start by illustrating the monthly vertical temperature profiles at the South Pole in SC-WACCM, averaged over the 500-yr preindustrial integration (Fig. 1). Clearly the stratospheric temperatures in the Antarctic exhibit a very large seasonal cycle, with a range of $\sim 70^{\circ} \mathrm{C}$ at $10 \mathrm{hPa}$. We also note that SC-WACCM successfully simulates a strong surface-based temperature inversion. As shown by S15 for observationally based temperature profiles, one can see that in certain months (January, February, March, October, November, and December) the SATs are colder than much of the overlying stratosphere $(\sim 10-1 \mathrm{hPa})$ : these are the months when an increase in $\mathrm{CO}_{2}$ concentrations is prone to yield an enhanced outgoing LW flux at the TOA, thus a negative $\mathrm{RF}_{\text {TOA:INST }}$.

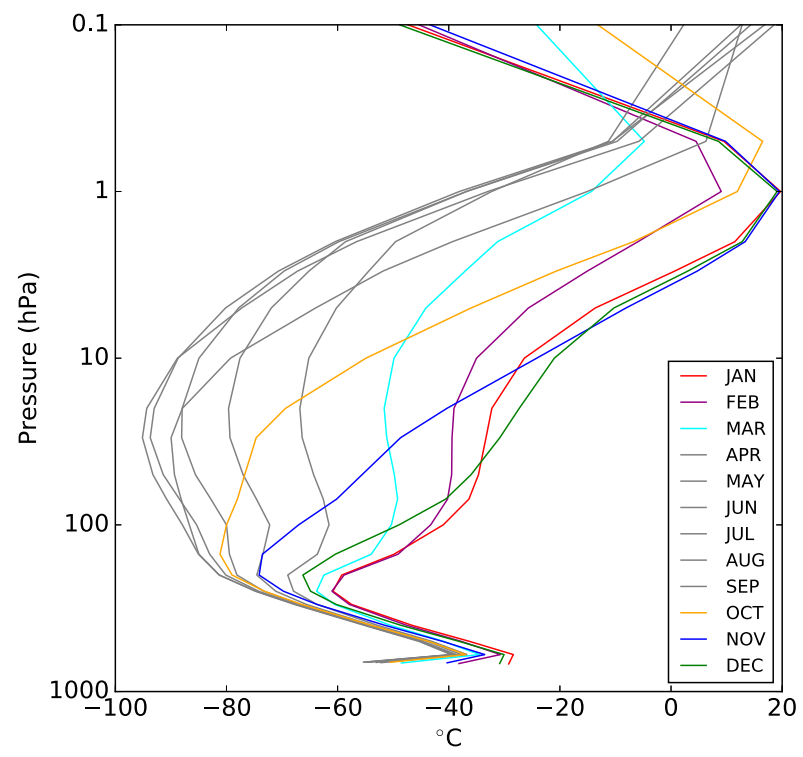

FIG. 1. Monthly vertical temperature profiles at the South Pole averaged over the 500-yr SC-WACCM preindustrial integration. Months that exhibit warmer stratospheric temperatures relative to surface temperatures are shown in the colored curves. All other months are shown as gray curves.

We now use the PORT model to examine whether these temperature profiles, in combination with increased $\mathrm{CO}_{2}$ concentrations, indeed lead to a negative $\mathrm{RF}_{\mathrm{TOA}: \mathrm{INST}}$ over Antarctica. In Fig. 2a we show the 12-month mean $\mathrm{RF}_{\text {TOA:INST }}$ associated with an instantaneous quadrupling of $\mathrm{CO}_{2}$. As reported in $\mathrm{S} 15$, we also clearly see a region of negative $\mathrm{RF}_{\mathrm{TOA}: \mathrm{INST}}$ over the high terrain of East Antarctica, where SATs are coldest. The seasons that contribute most to this 12-month mean signal are December-February (DJF) and SON, the same seasons for which the climatological temperature profiles exhibit substantially warmer stratospheric temperatures relative to the surface (see Fig. S1 in the online supplemental material).

To transcend the limitations of PORT, and confirm the existence of this negative $\mathrm{RF}_{\mathrm{TOA}: \mathrm{INST}}$, we next turn to the fully coupled SC-WACCM integrations, in which the climate system is allowed to respond to the imposed $\mathrm{CO}_{2}$ forcing (recall that PORT assumes fixed dynamical heating above the tropopause, and keeps all tropospheric and surface properties fixed). The $\mathrm{RF}_{\text {TOA:INST }}$ in SC-WACCM is shown in Fig. 2 d. Recall that Fig. $2 d$ shows the ensemble mean of the 12-month mean response. Clearly, PORT and SC-WACCM are in excellent agreement, as one might expect for these very early times after the stepwise increase in $\mathrm{CO}_{2}$ concentrations.

Figures $2 \mathrm{a}$ and $2 \mathrm{~d}$, therefore, confirm the findings of $\mathrm{S} 15$, and leave little doubt as to the existence of a 

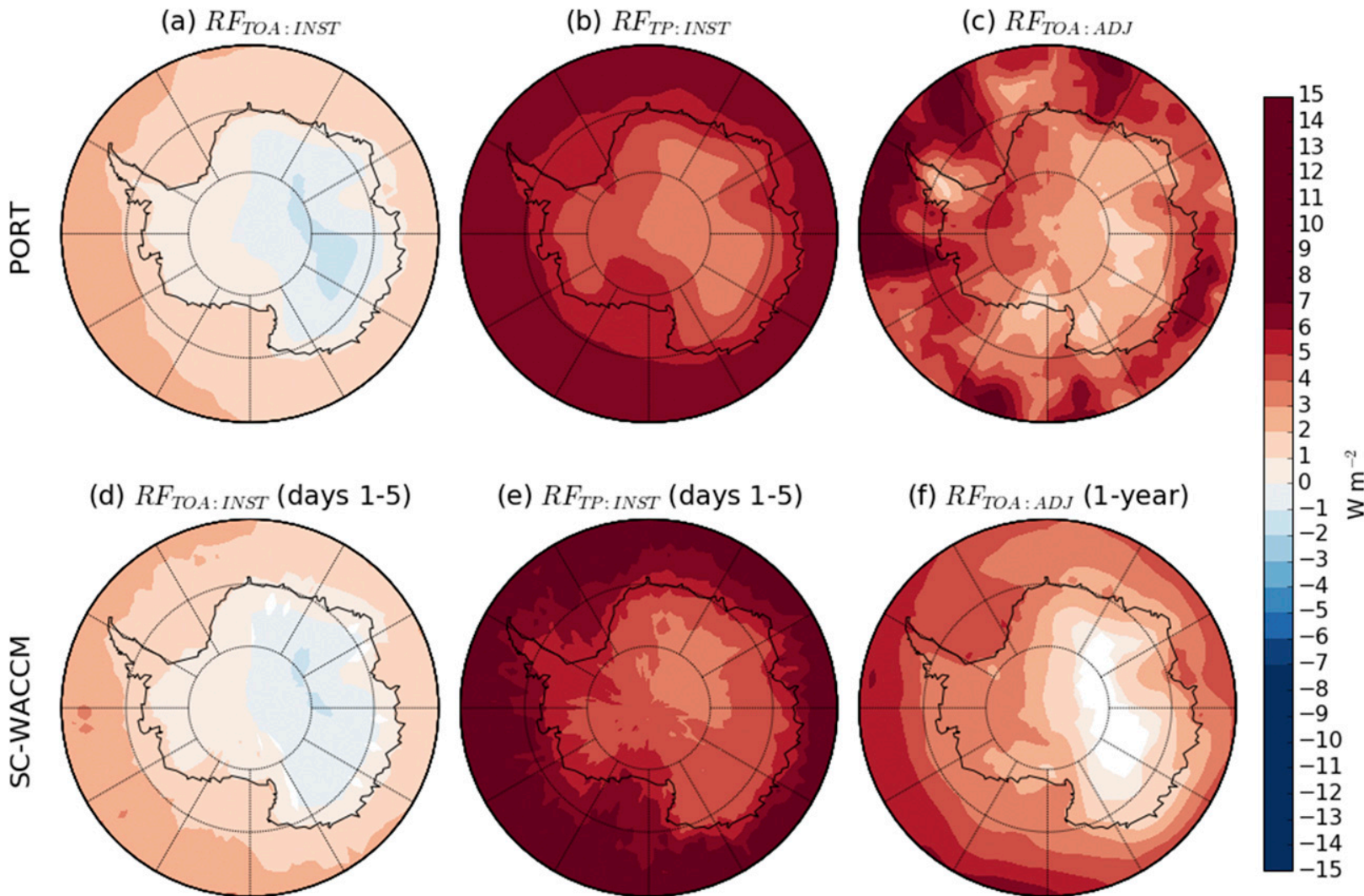

(d) $R F_{T O A: I N S T}$ (days 1-5)
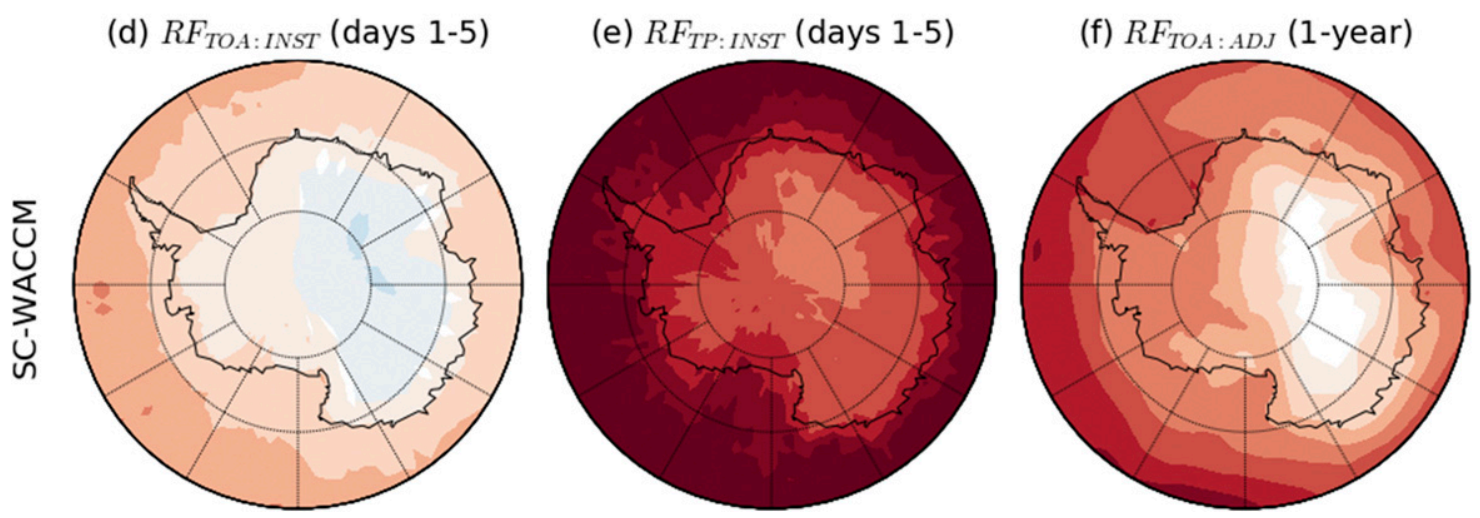

FIG. 2. (top) Shown are the (a) 12-month mean $\mathrm{RF}_{\text {TOA:INST, }}$ (b) 12-month mean $\mathrm{RF}_{\mathrm{TP}: I N S T}$, and (c) $\mathrm{RF}_{\mathrm{TOA}}$ :INST (1-yr averaged) for the PORT integrations. (bottom) Ensemble and 12-month mean (d) $\mathrm{RF}_{\mathrm{TOA}: \mathrm{INST}}$ (averaged over days 1-5), (e) RF $\mathrm{F}_{\mathrm{TP} \text { :INST }}$ (averaged over days 1-5), and (f) $\mathrm{RF}_{\mathrm{TOA}: \mathrm{ADJ}}\left(1-\mathrm{yr}\right.$ averaged) for the SC-WACCM integrations. $\mathrm{RF}_{\mathrm{TP}: I N S T}$ is calculated inline in PORT and is provided as an output field. In SC-WACCM, we have estimated $\mathrm{RF}_{\mathrm{TP} \text { :INST }}$ offline by integrating the three-dimensional LW heating rates using the logpressure vertical coordinate and log-pressure density to calculate $\Delta F_{\mathrm{TP}: \mathrm{LW}}$. Downward fluxes are positive. White shading indicates regions that are not statistically significant at the $95 \%$ level.

negative $\mathrm{RF}_{\mathrm{TOA}: \mathrm{INST}}$ over Antarctica following $4 \times \mathrm{CO}_{2}$. While this is intriguing, it is widely appreciated that the instantaneous radiative forcing at the tropopause, $\mathrm{RF}_{\mathrm{TP}: I N S T}$, or the stratosphere-adjusted radiative forcing, $\mathrm{RF}_{\mathrm{TOA}: \mathrm{ADJ}}$, are the more relevant quantities in terms of surface climate change (Hansen et al. 1997). We now turn our attention to these quantities.

Figure $2 b$ is identical to Fig. 2a except that we now show $\mathrm{RF}_{\text {TP:INST }}$. We clearly see that $\mathrm{RF}_{\text {TP:INST }}$ is positive everywhere over the Antarctic continent. Similarly, $\mathrm{RF}_{\text {TP:INST }}$ in SC-WACCM is very similar to the one in PORT (Fig. 2e). The disappearance of the region of negative radiative forcing over East Antarctica, when examined at the tropopause, indicates that the LW emission contributing to the negative $\mathrm{RF}_{\mathrm{TOA} \text { :INST }}$ comes entirely from the stratosphere.

Stratospheric temperatures rapidly cool in response to a quadrupling of $\mathrm{CO}_{2}(\sim 10-20 \mathrm{~K}$ between 10 and $1 \mathrm{hPa}$ in the first two months in our PORT and SC-WACCM integrations; see Fig. S2), and this cooling erodes the temperature difference between the surface and the stratosphere that is required to maintain the negative $\mathrm{RF}_{\text {TOA:INST }}$ over Antarctica.

The rapid cooling of the stratosphere has a dramatic effect on the response of the TOA LW fluxes to $4 \times \mathrm{CO}_{2}$. This is seen in Fig. 2c, where $\mathrm{RF}_{\mathrm{TOA}: \mathrm{ADJ}}$ computed from PORT is shown, in the 12-month mean. Clearly, all regions of negative $\mathrm{RF}_{\mathrm{TOA}: I N S T}$ disappear when stratospheric temperatures are allowed to adjust to $4 \times \mathrm{CO}_{2}$, in

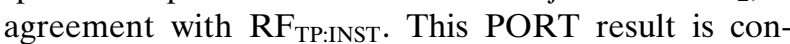
firmed by the fully coupled SC-WACCM integrations, for which $\mathrm{RF}_{\mathrm{TOA}: \mathrm{ADJ}}$ is shown in Fig. 2f. A region of statistically insignificant $\mathrm{RF}_{\mathrm{TOA}: \mathrm{ADJ}}$ is seen over East Antarctica (white areas in Fig. 2f), a remnant of the negative $\mathrm{RF}_{\text {TOA:INST }}$ combined with strong surface warming in this region (Fig. 4b), which enhances the LW emission to space.

$\mathrm{We}$, therefore, arrive at the following key result: when the stratosphere is allowed to adjust, the $\mathrm{RF}_{\mathrm{TOA}: \mathrm{INST}}$ of $4 \times \mathrm{CO}_{2}$ disappears, even over the highest locations in East Antarctica. To better understand this result, we examine the seasonal evolution of the instantaneous 
(a) $R F_{T O A: I N S T}$ and $\triangle S A T$ (days 1-5)

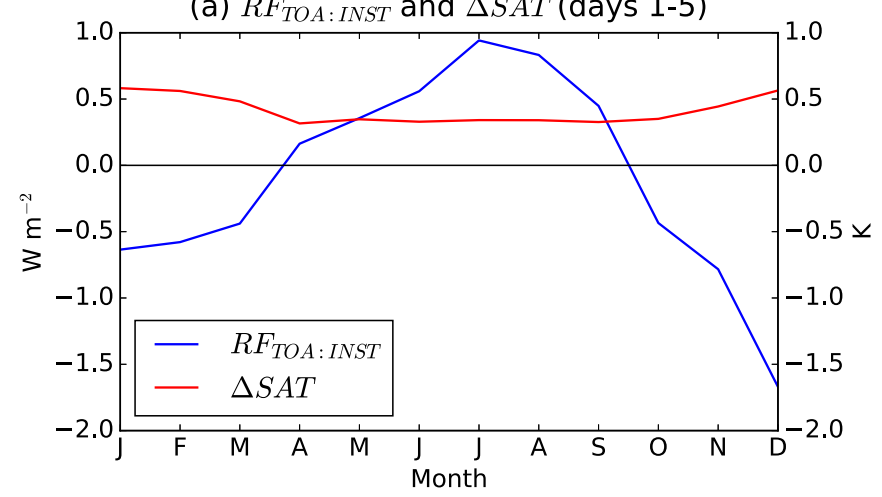

(b) Number of days with $\Delta F_{T O A: L W}<0$

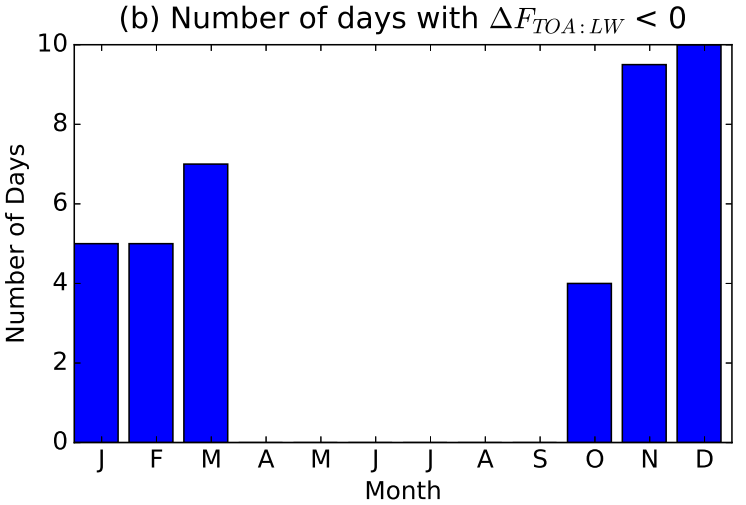

FIG. 3. East Antarctic area-averaged ensemble-mean seasonal cycle of (a) $\mathrm{RF}_{\mathrm{TOA}: I N S T}$ and $\Delta \mathrm{SAT}$ averaged over days $1-5$ of the SC-WACCM integrations and (b) duration (in days) of negative $\Delta F_{\mathrm{TOA}: \mathrm{LW}}$ (i.e., radiative forcing at the TOA) in the SC-WACCM integrations.

$\mathrm{RF}_{\mathrm{TOA}: I N S T}$. The ensemble mean $\mathrm{RF}_{\mathrm{TOA}: \mathrm{INST}}$, for each month, area-averaged over East Antarctica (Fig. S4) and over the first 5 days of the SC-WACCM integrations, is shown by the blue line in Fig. 3a. As already noted, it is negative over only 6 months of the year. More importantly, however, even in those months the negative $\mathrm{RF}_{\text {TOA:INST }}$ is very short lived. In Fig. 3b, we show the number of days over which $\Delta F_{\text {TOA:LW }}$ is negative, for each month separately. Clearly, the negative values over East Antarctica disappear in less than 10 days in most months. This is because stratospheric adjustment is very fast: in our SC-WACCM integrations, $20 \%$ of the final cooling at $10 \mathrm{hPa}$ occurs in the first 5 days after quadrupling of $\mathrm{CO}_{2}$ (Fig. S2).

We next turn our attention from the TOA to the surface, and ask the question that provides the ultimate motivation for this entire exercise: Can a large increase in $\mathrm{CO}_{2}$ actually lead to a surface cooling anywhere in Antarctica? Based on the above analysis, we do not expect any cooling at the surface in response to $4 \times \mathrm{CO}_{2}$. Using our SC-WACCM integrations, we can now verify this directly. In other words, we can ask this: Is there any evidence for surface cooling in the initial few days after we quadruple $\mathrm{CO}_{2}$, when a statistically significant negative $\mathrm{RF}_{\mathrm{TOA} \text { :INST }}$ is present in certain seasons?

The answer to this question is given in Fig. 4a, where we plot the ensemble mean and 12-month mean SAT response to $4 \times \mathrm{CO}_{2}$ in SC-WACCM, averaged over the first five days of the integrations. Despite a negative $\mathrm{RF}_{\text {TOA:INST }}$ over East Antarctica, we find surface warming throughout the continent. Furthermore, the surface warming is present in all months (see Fig. 3a, red curve). In addition, we find a weak but statistically significant negative correlation between the magnitude of East Antarctic $\mathrm{RF}_{\mathrm{TOA}: I N S T}$ and $\triangle \mathrm{SAT}$ averaged over the first five days, across all ensemble members (see Fig. S3). If the negative $\mathrm{RF}_{\text {TOA:INST }}$ caused a cooling (or weaker warming) of the Antarctic surface, we would expect a positive
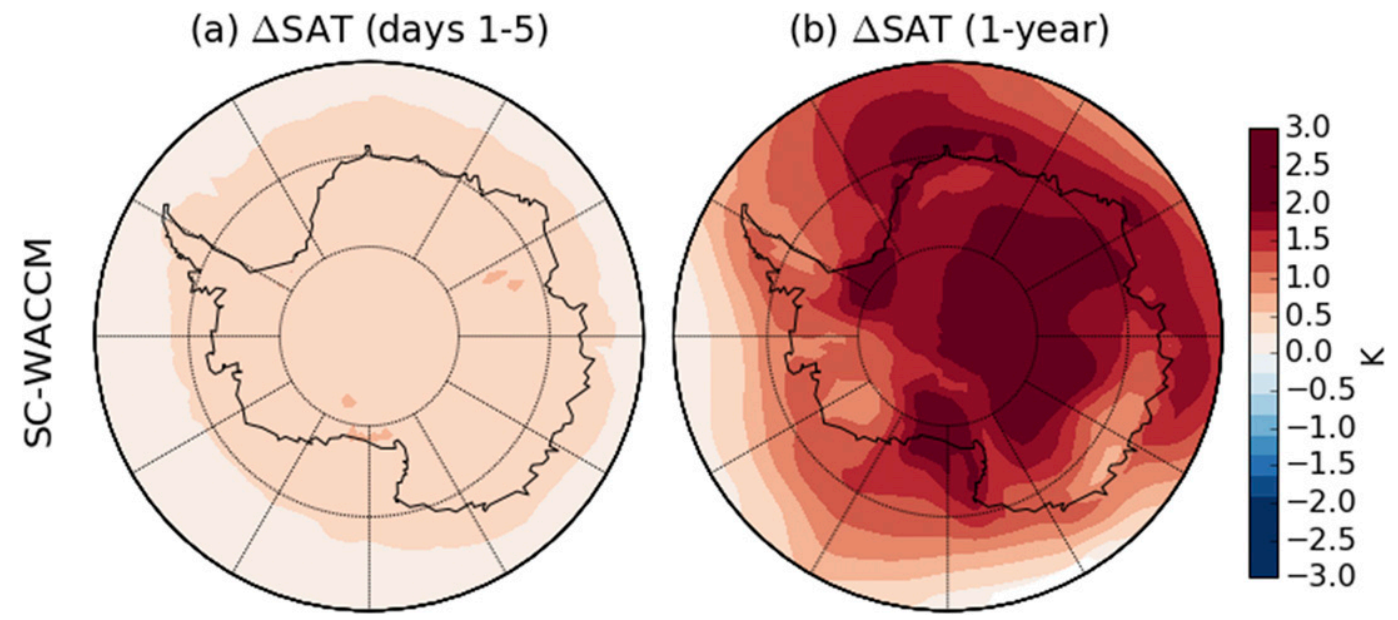

FIG. 4. Ensemble and 12-month mean $\triangle$ SAT (a) averaged over days 1-5 and (b) 1-yr-averaged for the SC-WACCM integrations. White shading indicates regions that are not statistically significant at the $95 \%$ level. 


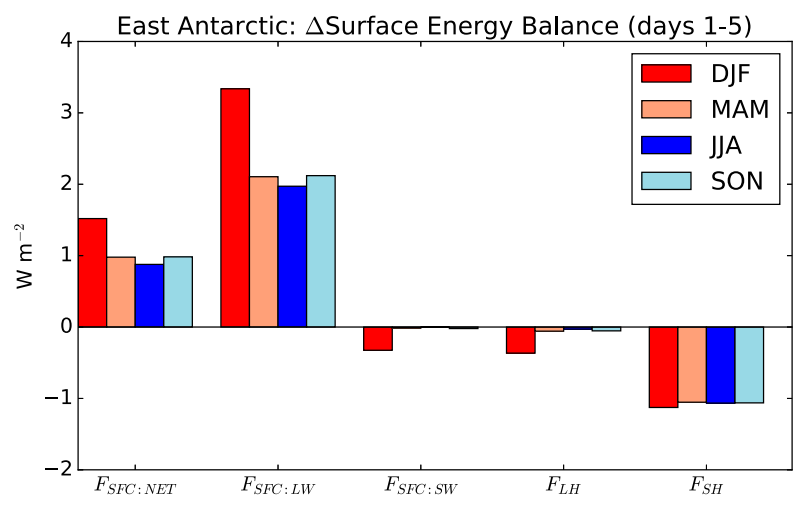

FIG. 5. East Antarctic area-averaged ensemble mean and 3-month mean differences in surface energy fluxes between the $4 \times \mathrm{CO}_{2}$ and preindustrial SC-WACCM integrations (net surface energy flux: $F_{\mathrm{SFC}: \mathrm{NET}}$, net surface longwave flux: $F_{\mathrm{SFC}: \mathrm{LW}}$, net surface shortwave flux: $F_{\mathrm{SFC}: \mathrm{Sw}}$, latent heat flux: $F_{\mathrm{LH}}$, and sensible heat flux: $F_{\mathrm{SH}}$ ) averaged over days 1-5. Downward fluxes are positive.

correlation. Thus, our model integrations reveal a complete lack of influence of the negative $\mathrm{RF}_{\text {TOA:INST }}$ on SAT in response to $4 \times \mathrm{CO}_{2}$. This is consistent with the $\mathrm{RF}_{\mathrm{TP}: \mathrm{INST}}$, which is positive everywhere over Antarctica in both the PORT and SC-WACCM integrations. (Figs. 2b,e). And, as one might expect at this point, the ensemble average SAT response over the entire year of the integrations also shows a warming throughout the entire Antarctic continent, as seen in Fig. 4b.

Finally, to elucidate the surface warming over East Antarctica in spite of the negative $\mathrm{RF}_{\mathrm{TOA}: \mathrm{INST}}$, we examine the surface energy budget. Figure 5 shows the ensemble mean and 3-month mean responses of surface fluxes to $4 \times \mathrm{CO}_{2}$ in SC-WACCM, averaged over the first five days of the integrations. We see that the difference in net surface energy flux is positive, and that the only positive contribution to this is from the net downward longwave radiative flux (recall that downward fluxes are positive). This enhanced downwelling LW flux is due almost entirely to elevated $\mathrm{CO}_{2}$ concentrations, and is attenuated slightly by a rapid adjustment of clouds (see Fig. S5). Thus, although the vertical temperature profiles over Antarctica in certain seasons give rise to enhanced outgoing LW fluxes at the TOA in response to $4 \times \mathrm{CO}_{2}$ (before the stratospheric temperatures adjust), the $\mathrm{RF}_{\mathrm{TP} \text { :INST }}$ and Fig. 5 clearly indicate that a strong enhancement of the downward LW flux dominates the surface energy budget response, and, therefore, leads to a warming of the Antarctic surface on all time scales.

\section{Conclusions}

We have here confirmed the existence of a negative $\mathrm{RF}_{\text {TOA:INST }}$ over Antarctica with increased $\mathrm{CO}_{2}$, reported in S15, using an offline radiative transfer model with temperature profiles taken from a stratosphereresolving GCM. Furthermore, we have extended the work of S15 to examine the instantaneous radiative forcing at the tropopause and the effect of stratospheric adjustment. Perhaps unsurprisingly, we find that the negative radiative forcing completely disappears when these more appropriate quantities are considered.

We have also considered the coupled climate response and the possible impact of rapid climate feedbacks using the fully coupled GCM integrations, and shown that the peculiar negative $R_{\text {TOA:INST }}$ does not result in any surface cooling at the Antarctic surface upon quadrupling of $\mathrm{CO}_{2}$ concentrations. This is due to the enhanced downward LW flux at the surface in response to $4 \times \mathrm{CO}_{2}$.

In closing, we note that our model integrations with a large and highly idealized forcing were not designed to precisely quantify how the negative $\mathrm{RF}_{\mathrm{TOA}}$ INST might have affected Antarctic surface climate in recent decades. That said, our findings suggest that it is highly unlikely that the robust surface cooling trend observed over East Antarctica in recent decades is caused by the negative $\mathrm{RF}_{\mathrm{TOA}: \mathrm{INST}}$ due to $\mathrm{CO}_{2}$. One final simple argument, relating to the seasonality of the observed Antarctic trends, supports our findings. The largest cooling trends in East Antarctica are found in austral autumn (MAM), whereas the strongest negative $\mathrm{RF}_{\text {TOA:INST }}$ occurs in austral spring and summer (SON and DJF; see Figs. 3a and S1). Recent work argues that the cooling trend appears to be inconsistent with any historical anthropogenic forcing, and suggests that internal climate variability may play an important role (Smith and Polvani 2017).

Acknowledgments. This work is supported by two awards (PLR-13-41657 and AGS-13-22439) from the U.S. National Science Foundation to Columbia University. The authors wish to express their gratitude to Dr. Stephen Warren, of the University of Washington, for bringing to their attention the work of Hanel et al. (1972). It is delightful, and a little humbling, to be able to revisit and expand upon a finding that is nearly half a century old.

\section{REFERENCES}

Bromwich, D. H., J. P. Nicolas, A. J. Monaghan, M. a. Lazzara, L. M. Keller, G. A. Weidner, and A. B. Wilson, 2013: Central West Antarctica among the most rapidly warming regions on Earth. Nat. Geosci., 6, 139-145, https://doi.org/10.1038/ ngeo1671.

Chapman, W. L., and J. E. Walsh, 2007: A synthesis of Antarctic temperatures. J. Climate, 20, 4096-4117, https://doi.org/ 10.1175/JCLI4236.1.

Clem, K. R., and R. L. Fogt, 2015: South Pacific circulation changes and their connection to the tropics and regional Antarctic 
warming in austral spring, 1979-2012.J. Geophys. Res. Atmos., 120, 2773-2792, https://doi.org/10.1002/2014JD022940.

- , and J. A. Renwick, 2015: Austral spring Southern Hemisphere circulation and temperature changes and links to the SPCZ. J. Climate, 28, 7371-7384, https://doi.org/10.1175/ JCLI-D-15-0125.1.

Conley, A. J., J.-F. Lamarque, F. Vitt, W. D. Collins, and J. Kiehl, 2013: PORT, a CESM tool for the diagnosis of radiative forcing. Geosci. Model Dev., 6, 469-476, https://doi.org/ 10.5194/gmd-6-469-2013.

Ding, Q., E. J. Steig, D. S. Battisti, and M. Küttel, 2011: Winter warming in West Antarctica caused by central tropical Pacific warming. Nat. Geosci., 4, 398-403, https://doi.org/10.1038/ ngeo1129.

Fogt, R. L., and A. J. Wovrosh, 2015: The relative influence of tropical sea surface temperatures and radiative forcing on the Amundsen Sea low. J. Climate, 28, 8540-8555, https://doi.org/ 10.1175/JCLI-D-15-0091.1.

Hanel, R. A., B. J. Conrath, V. G. Kunde, C. Prabhakara, I. Revah, V. V. Salomonson, and G. Wolford, 1972: The Nimbus 4 infrared spectroscopy experiment: 1 . Calibrated thermal emission spectra. J. Geophys. Res., 77, 2629-2641, https://doi.org/ 10.1029/JC077i015p02629.

Hansen, J., M. Sato, and R. Ruedy, 1997: Radiative forcing and climate response. J. Geophys. Res., 102, 6831-6864, https:// doi.org/10.1029/96JD03436.

Kay, J. E., and Coauthors, 2015: The Community Earth System Model (CESM) Large Ensemble Project: A community resource for studying climate change in the presence of internal climate variability. Bull. Amer. Meteor. Soc., 96, 1333-1349, https://doi.org/10.1175/BAMS-D-13-00255.1.

Li, X., D. M. Holland, E. P. Gerber, and C. Yoo, 2014: Impacts of the north and tropical Atlantic Ocean on the Antarctic Peninsula and sea ice. Nature, 505, 538-542, https://doi.org/ 10.1038/nature12945.

Marsh, D. R., M. J. Mills, D. E. Kinnison, J.-F. Lamarque, N. Calvo, and L. M. Polvani, 2013: Climate change from 1850 to 2005 simulated in CESM1(WACCM). J. Climate, 26, 73727391, https://doi.org/10.1175/JCLI-D-12-00558.1.

Marshall, G. J., 2007: Half-century seasonal relationships between the southern annular mode and Antarctic temperatures. Int. J. Climatol., 27, 373-383, https://doi.org/10.1002/joc.1407.

Marshall, J., and R. A. Plumb, 2007: Atmosphere, Ocean and Climate Dynamics: An Introductory Text. Academic Press, 344 pp.

McLandress, C., T. G. Shepherd, J. F. Scinocca, D. A. Plummer, M. Sigmond, A. I. Jonsson, and M. C. Reader, 2011: Separating the dynamical effects of climate change and ozone depletion. Part II: Southern Hemisphere troposphere. J. Climate, 24, 1850-1868, https://doi.org/10.1175/2010JCLI3958.1.

Monaghan, A. J., D. H. Bromwich, and D. P. Schneider, 2008: Twentieth century Antarctic air temperature and snowfall simulations by IPCC climate models. Geophys. Res. Lett., 35, L07502, https://doi.org/10.1029/2007GL032630.

Nicolas, J. P., and D. H. Bromwich, 2014: New reconstruction of Antarctic near-surface temperatures: Multidecadal trends and reliability of global reanalyses. J. Climate, 27, 8070-8093, https://doi.org/10.1175/JCLI-D-13-00733.1.

O'Donnell, R., N. Lewis, S. McIntyre, and J. Condon, 2011: Improved methods for PCA-based reconstructions: Case study using the Steig et al. (2009) Antarctic temperature reconstruction. J. Climate, 24, 2099-2115, https://doi.org/ 10.1175/2010JCLI3656.1.

Schmithüsen, H., J. Notholt, G. König-Langlo, P. Lemke, and T. Jung, 2015: How increasing $\mathrm{CO}_{2}$ leads to an increased negative greenhouse effect in Antarctica. Geophys. Res. Lett., 42, 10 422-10 428, https://doi.org/10.1002/2015GL066749.

Schneider, D. P., C. Deser, and Y. Okumura, 2012: An assessment and interpretation of the observed warming of West Antarctica in the austral spring. Climate Dyn., 38, 323-347, https:// doi.org/10.1007/s00382-010-0985-x.

Simpkins, G. R., S. McGregor, A. S. Taschetto, L. M. Ciasto, and M. H. England, 2014: Tropical connections to climatic change in the extratropical Southern Hemisphere: The role of Atlantic SST trends. J. Climate, 27, 4923-4936, https://doi.org/ 10.1175/JCLI-D-13-00615.1.

Smith, K. L., and L. M. Polvani, 2017: Spatial patterns of recent Antarctic surface temperature trends and the importance of natural variability: Lessons from multiple reconstructions and the CMIP5 models. Climate Dyn., $\mathbf{4 8}$, 2653-2670, https://doi.org/10.1007/s00382-016-3230-4.

_ R. R. Neely, D. R. March, and L. M. Polvani, 2014: The Specified Chemistry Whole Atmosphere Community Climate Model (SC-WACCM). J. Adv. Model. Earth Syst., 6, 883-901, https://doi.org/10.1002/2014MS000346.

Steig, E. J., D. P. Schneider, S. D. Rutherford, M. E. Mann, J. C. Comiso, and D. T. Shindell, 2009: Warming of the Antarctic ice-sheet surface since the 1957 International Geophysical Year. Nature, 457, 459-462, https://doi.org/10.1038/ nature 07669 .

Thompson, D. W. J., and S. Solomon, 2002: Interpretation of recent Southern Hemisphere climate change. Science, 296, 895-899, https://doi.org/10.1126/science.1069270. 